\title{
MATHEMATICAL MODELING AND CONTROL SYSTEM OF NEARLY ZERO ENERGY BUILDING
}

\author{
Ildar A. Sultanguzin ${ }^{1}$, Hannes Toepfer ${ }^{2}$, Ivan D. Kalyakin ${ }^{1}$, Alexandr V. Govorin ${ }^{1}$, \\ Ekaterina V. Zhigulina ${ }^{1}$, Sergey Yu. Kurzanov ${ }^{1}$, Yury V. Yavorovsky ${ }^{1}$ \\ ${ }^{1}$ Department of Industrial Thermal Engineering Systems, National Research University “MPEI”, ${ }^{2}$ Institute for Information Technology, Technische Universität Ilmenau
}

Abstract. The article examines three different kinds of mathematical model of nearly zero energy building. The first model enables to optimize the structure and the definition of key parameters of energy efficient building. The second model is necessary for passive house designing with renewable energy sources. The third model should be used for monitoring and control of energy supply system of nearly zero energy building through year every hour of winter and summer.

Keywords: control system, mathematical model, monitoring, passive house, zero energy building

\section{MODELOWANIE MATEMATYCZNE I SYSTEM STEROWANIA BUDYNKIEM NIEMAL ZEROENERGETYCZNYM}

Streszczenie. $W$ artykule rozważono trzy różne typy matematycznego modelu budynku o niemal zerowym zużyciu energii. Pierwszy model pozwala zoptymalizować strukturę $i$ definicję kluczowych parametrów budynku energooszczędnego. Drugi model jest niezbędny do zaprojektowania domu pasywnego wykorzystujacego odnawialne źródła energii. Trzeci model powinien być stosowany do godzinowego monitorowania i monitorowania systemu energetycznego budynku o niskim zużyciu energii przez cały rok.

Słowa kluczowe: układ sterowania, model matematyczny, monitoring, dom pasywny, budynek zeroenergetyczny

\section{Introduction}

The $4^{\text {th }}$ industrial revolution is a stage of development, which spreads new abilities in science, technologies, life. And the more benefits it provides, the more knowledge is to be known, the more information is to be managed. At present, when we are trying to reduce energy consumption by developing old or creating new technologies, it is vital to modernize the main consumers - buildings, where we live. Year by year buildings become bigger, the amount of occupants is growing, which makes all systems more complicated.

In current work the subject of research is a two-storey nearly zero house with $160 \mathrm{~m}^{2}$ of living space. The design of its energy supply system can be divided in three stages:

- selection of technologies, which are nearest to optimum;

- creation of mathematical model for each configuration;

- data collection and control system.

\section{Optimization model}

In Russia construction of energy-efficient buildings with minimum energy consumption - is one of the basic tasks in solving of energy saving problems. Here optimum solutions are to be estimated for north, moderate and south climate zones taking into account their specific characteristics.

The solution for the optimization task through a mathematical model allows to determine the optimum parameters of energy supply system at which power independence of the considered object would be reached. It will allow to use the renewable energy and to preserve fossil fuels that is urgent because of existing reserves exhaustion

The problem of optimization of creation of energy efficient buildings $[4,10]$ analogously with the optimization problem of integrated steelworks and heat power installations [11] could be formulated as follows (1) - (6).

A problem concerning optimization of the energy supply system of building could be formulated as a mathematical problem in the following manner.

It is necessary to determine such parameters $X$ and a type of the thermal scheme $S$ that is

with constraints

$$
C_{\Sigma}=F\left(X, Y(X), Z_{K}, S, A\right) \rightarrow \min
$$

- in the form of equations

- in the form of inequalities

$$
E(X, Y(X))=0
$$

$$
Y^{*}<Y(X)<Y^{* *}
$$

optimized parameters:

of energy sources

$$
X_{\text {SOUR }} *<X_{\text {SOUR }}<X_{\text {SOUR }} * *
$$

of energy saving technologies

$$
\begin{aligned}
& X_{T E C H} *<X_{T E C H}<X_{T E C H} * * \\
& X_{S T O R} *<X_{S T O R}<X_{S T O R} * *
\end{aligned}
$$

for $A=A_{0}$, where $X-$ is a set of independent parameters, $Y-$ is a set of the dependent parameters determined through system of the equations (2).

In order that energy efficiency optimization was conducted by the form of the thermal scheme of power technologies at building, it is necessary that the indicator $S$ includes all possible varieties of thermal schemes types defined as a result of the analysis of functioning of energy supply system. Indicators of external factors at the solution of this task are considered to be set, i.e. $A=A_{0}$. Mainly the climatic conditions, technical and economic values necessary for determination of separate elements of the power equipment costs, costs of fuel, depreciation, repair, etc. enter set of indicators $A$.

As criterion of optimization $C_{\Sigma}$ the minimum of the total expenses including capital and operational expenditure for construction and the equipment, cost of the consumed energy resources and damage from impact of harmful emissions on the environment during the building life cycle could be chosen.

As the optimized parameters $X$ could be used:

- various energy resources (natural gas, biomass, electric power, solar energy, wind power, warmth of soil, etc.);

- modern construction materials (gas-concrete blocks, mineral basalt wool, expanded polystyrene, polyurethane foam, etc.);

- energy saving technologies (heat pumps, recuperation of air and water waste heat, solar collector, solar photovoltaic (PV) panels, wind power installations);

- covering of basic and pick loads for energy supply of building (heating, hot water supply, ventilation, conditioning, power supply);

- volume of energy storages (the accumulators of hot water, rechargeable batteries, compressed air energy storage, etc.).

The solution of an optimizing task on mathematical model will allow determining the optimum parameters of energy supply system at which power independence of the considered object would be reached. It will allow preserving fossil fuels that is urgent at exhaustion of their reserves. 


\section{Passive House Model}

The designing mathematical model is created in PHPP (Passive House Planning Package) and designPH software [3, 6], and it allows find the parameters of energy supply system with the lowest energy consumption (see Fig. 1).

According to passive house concept and PHPP software we could find decision which allows to decrease the energy consumption to $38 \mathrm{kWh} /\left(\mathrm{m}^{2} \mathrm{a}\right)$ [10]. Next step is the active house concept implementation for designing nearly zero energy building, based on the renewable energy resources (solar energy, wind energy).

In current work the subject of research is a two-storey net zero house with $160 \mathrm{~m}^{2}$ of living space. The designing of its energy system can be divided in three stages:

- selection of technologies, which are the nearest to optimum;

- creation of mathematical model for each configuration;

- data manipulation.
Configuration with geothermal heat pump as main energy source and gas boiler as auxiliary, solar collectors, photovoltaic panels as additional renewable energy source was selected. The mathematical model is created in PHPP (Passive House Planning Package) and designPH software, and it allows to find parameters of system with the lowest energy consumption.

The results of energy demand calculations for different system configurations are presented in the Table Configuration "Compact heat pump (HP) unit" ("compact heat pump") means the usage the air heat that is removed from the premises as the low-grade heat source.

Configuration with geothermal heat pump as main energy source, wooden fireplace, gas boiler, ventilation with heat recovery, solar collectors, photovoltaic panels, as auxiliary energy sources has been selected (Fig. 2).

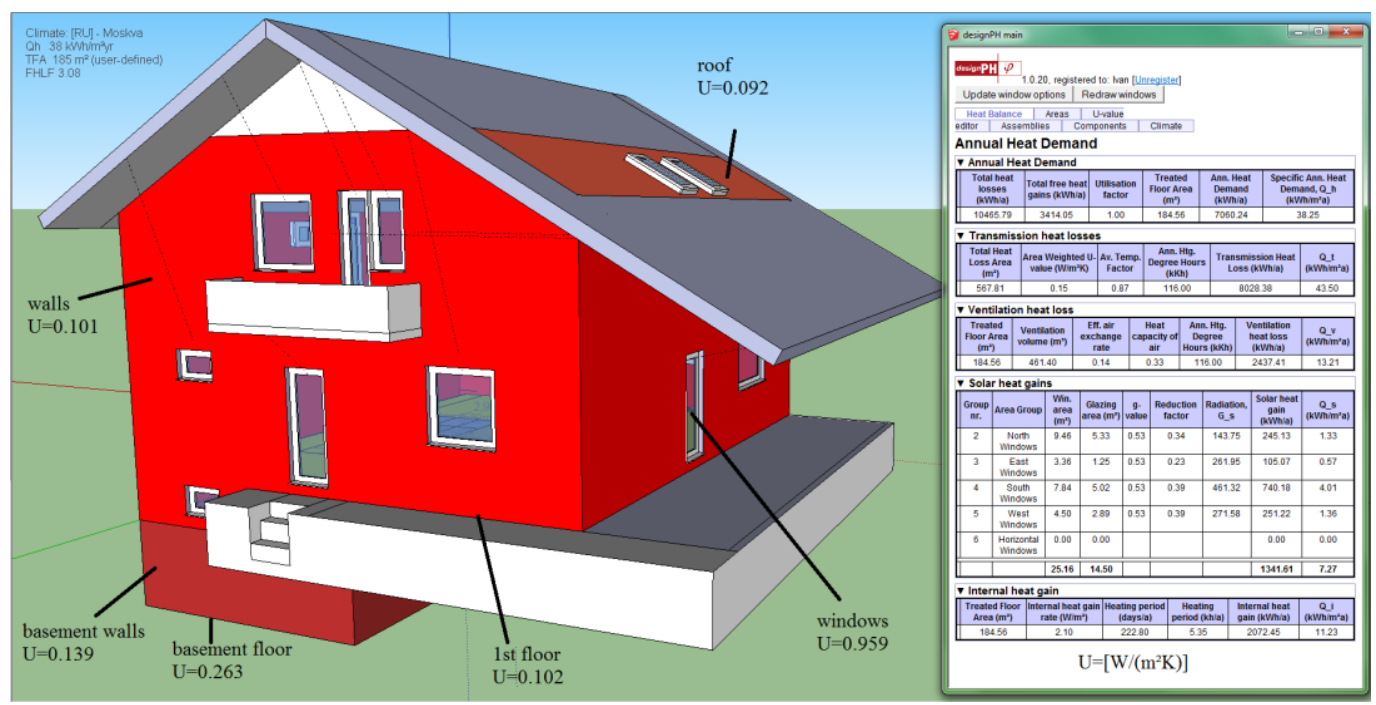

Fig. 1. Result of design of building in design PH and PHPP software

Table 1. Results of energy demand calculations for different system configurations

\begin{tabular}{|c|c|c|c|c|}
\hline & Geothermal heat pump & Gas boiler & „Compact HP unit” & Water-air heat pump \\
\hline Primary energy demand, $\frac{k W \cdot h}{a}$ & 8089 & 13099 & 10004 & 13233 \\
\hline Specific primary energy demand, $\frac{k W \cdot h}{m^{2} \cdot a}$ & 108 & 126 & 113 & 135 \\
\hline Specific space heating energy demand, $\frac{k W \cdot h}{m^{2} \cdot a}$ & 42 & 46 & 42 & 41 \\
\hline
\end{tabular}

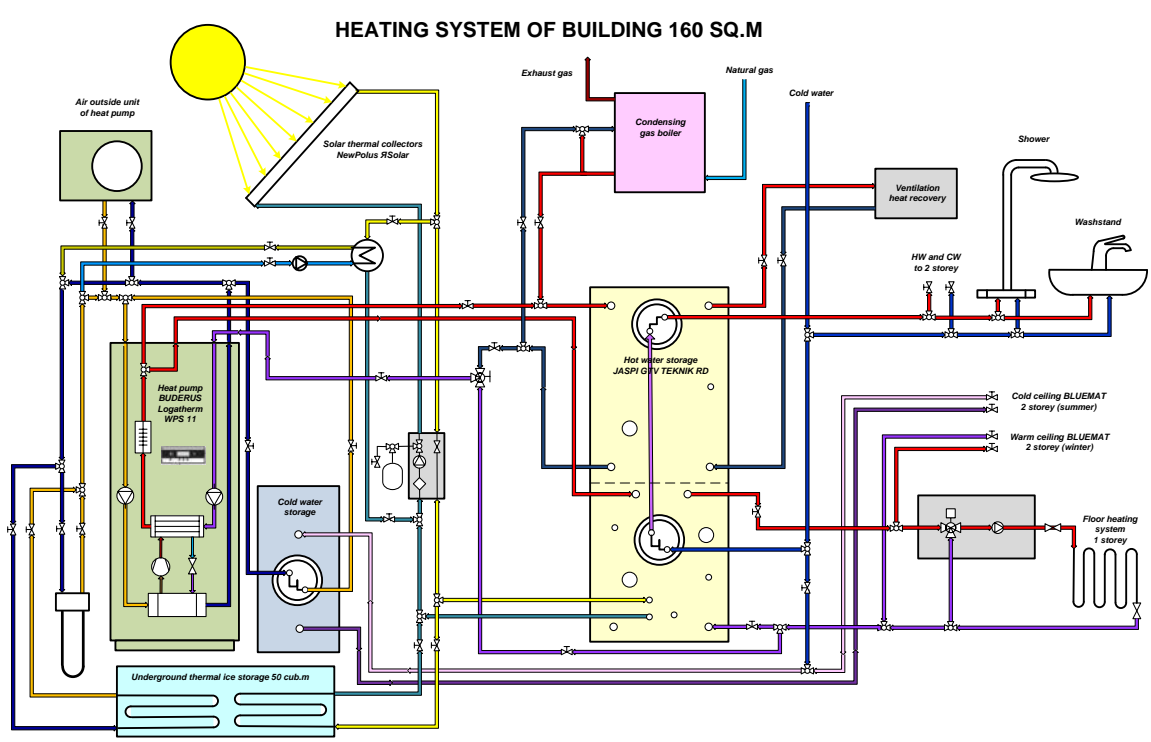

Fig. 2. Heating system of the building under consideration 


\section{Monitoring and control system}

The next stage is to define how to collect sensory information and to influence the required element, how to manage data and to control all the parameters in every significant part of energy supply system. The creation of monitoring and control system has a great importance.

Now the task is to create a model of control system and define its optimal configuration for the most effective exploitation of energy supply system in winter and summer. The main problem of multi-energy systems in buildings is to combine the performance of different sources of energy to hold comfortable microclimatic parameters and achieve nearly zero energy balance any time. And beside the problem of energy streams management at present moment, there is more significant one - season energy storage. The remote operation should be organized in order to minimize the energy consumption in periods when the building is vacant.

Automated building management system (BMS) is designed to automate the processes and operations that are implemented in modern buildings. In literature BMS usually implies the automation of building engineering systems: ventilation, heating and air conditioning, water supply and sewerage, electricity and lighting, etc.

There are upper level and lower level organization of the smart home (see Fig. 3). The upper level is the interaction of man and control your smart home based on interfaces. The lower level is the direct interaction of a unified system of collecting and processing information and various device-based data transfer protocols. Data transfer protocol - a set of agreements interface logic levels that define the data exchange between different programs.

Wired and wireless protocols have a number of advantages and disadvantages. Wired ones require a large number of wires around the house for all appliances, but less susceptible to interference like wireless and have significantly less electromagnetic impact on human health. It is quite easy to organize wireless protocols, that almost do not require the carrying out communications with the exception of power supply.

The project of Building Management System (BMS) [9] implies realization of intelligent climate, lighting, appliances and security controls that consider and comprise the following:

- heat load regulators depending on the outdoor air temperature and on the individual schedules,

- load redistribution between the systems when using the multiple energy systems in the building,

- safety sensors usage for water overheating in the heating circuit, prevention burner extinction,

- intelligent control of water flow, of water turning off, of heating water in the tanks batteries, depending on the schedule and consumption,

- intelligent control of the lighting will include controlling not only the switching on and off lighting, but also the position of the curtains, shutters and blinds,

- intelligent control of electrical appliances,

- security sensors application: sensors of gas contamination, fire, flooding.

For thermal and electric energy saving in heating, ventilation and air-conditioning there should be organized daily parameters control in each room, given the people presence and working in the premises of various household appliances and lighting, insulation, open doors.

Thermal and electric energy savings for heating hot water can be achieved by taking into account the consumption during the day and thereby regulating the amount of hot water supply during the day. It is possible to provide the flow of hot and cold water directly to the moment when it is used, same as it is organized in public areas in order to save heat, electricity and water consumption. In case of damage or depressurization of the water system the water flow should be stopped.

Energy savings can be achieved by automatic disconnection of lighting in those areas where there are no people or in those areas where sufficient illumination through daylight. Savings could be achieved by de-energizing part of the smart building system that is not used. Also there should be created profiles with settings for a specific user or a specific situation for better efficiency and convenience.

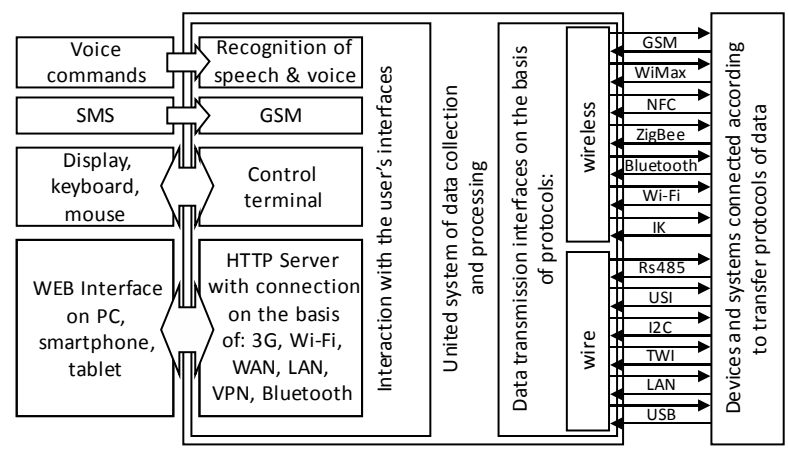

Fig. 3. Key diagram of the scheduled intelligent house organization

It is possible to achieve high-quality results on energy saving and comfortable living due to integration data systems into a unified system of collecting and processing information.

The principle of creating and functioning of the road traffic system management monitoring based on wireless sensors and data transmission via Internet [12] can be used in monitoring systems and smart house management. In particular, on the basis of meteorological forecast for $1-2$ days obtained via the Internet may be the best option for the energy system of the smart home. When the weather forecast is changing, then the control programs of the energy supply system of the smart house will also be changed. The system of smart environments for energy savings consist of sensors embedded in an environment that allow a control system to perceive its current state [13].

The method for forecasting the load for space heating in a single-family house is presented in [1]. The forecasting model is built using data from houses located in Denmark, combined with local climate measurements and weather forecasts. Every hour the hourly heat load for each house the following two days is forecasted. Identification of a model, which is suitable for all the houses, is carried out. New approach to online forecasting of power production from PV systems explains in [2]. The suggested method is a two-stage method where first a statistical normalization of the solar power is obtained using a clear sky model. In the work [13] the heat dynamics of a storage tank were modelled on the basis of data and maximum likelihood methods. The grey-box model was used for Economic Model Predictive Control (MPC) of the energy in the tank. The control objective was to balance the energy from a solar collector and the heat consumption in a residential house. It is proposed to integrate a price-sensitive control to enable the storage tank to serve a smart energy system in which flexible consumers are expected to help balance fluctuating renewable energy sources like wind and solar. Through simulations, the impact of applying Economic MPC shows annual electricity cost savings up to $25-30 \%$ [7].

Another work [15] shows that the building automation systems (BAS) are capable of managing building operational performance in an efficient and convenient way. The amount of realtime monitoring and control data in BAS grows continually in the building life cycle, which stimulates an intense demand for powerful big data analysis tools in BAS. Time series data mining methodology for temporal knowledge discovery in big BAS data is presented in this paper. The methodology has been applied to analyze the BAS data retrieved from a real building.

Large amounts of data are increasingly accumulated in the energy sector with the continuous application of sensors, wireless transmission, network communication, and cloud computing technologies [5]. It considers the sources and characteristics of energy big data. Also, a process model of big data driven smart energy management is proposed. There are four important aspects of BAS: power generation side management, microgrid 
and renewable energy management, asset management and collaborative operation, as well as demand side management. It points out the challenges of big data-driven smart energy management in IT infrastructure, data collection and governance, data integration and sharing, processing and analysis, security and privacy, and professionals [5]. It is necessary to use the system approach of big data analysis for smart energy management on the base of the last investigations in the field of monitoring and control systems $[1,2,5,7,8,12-15]$.

\section{Conclusion}

The investigated nearly zero energy building has been examined by means of three different kinds of mathematical

\section{References}

[1] Bacher P., Madsen H., Nielsen H.A., Perers B.: Short-term heat load forecasting for single family houses. Energy and Buildings 38/2006, 63-71.

[2] Bacher P., Madsen H., Nielsen H.A.: Online short-term solar power forecasting. Solar Energy 83/2009, 1772-1783.

[3] Cemesova A. et al.: PassivBIM: Enhancing interoperability between BIM and low energy design software. Automation in Construction 57/2015, 17-32.

[4] Fabrizio E. et al.: A model to design and optimize multi-energy systems in buildings at the design concept stage. Renewable Energy 35/2010, 644-655.

[5] Fan Ch. et al.: Temporal knowledge discovery in big BAS data for building energy management. Energy and Buildings 109/2015, 75-89.

[6] Feist V.: Die Hauptlagen nach der Projektierung der passiven Häuser. Konti Print, Moscow 2015

[7] Halvgaard R. et al:: Model predictive control for a smart solar tank based on weather and consumption forecasts. Energy Procedia 30/2012, 270-278.

[8] Michailidis I.T. et al.: Proactive control for solar energy exploitation: A german high-inertia building case study. Applied Energy 155/2015, 409-420.

[9] Oti A.H. et al.: A framework for the utilization of Building Management System data in building information models for building design and operation. Automation in Construction 72/2016, 195-210.

[10] Sultanguzin I., Kalyakin I., Govorin A., et.al.: Optimization of the energy efficient active house. 3 Ingenieurtag 2016. Neseff-Netzwerktreffen 2016. Tagungsband. Branden-burgische Technische Universität. Cottbus-Senftenberg. 14-15 November 2016, 8-12.

[11] Sultanguzin I.A., Isaev M.V., Kurzanov S.Yu.: Optimizing the production of coke, coal chemicals, and steel on the basis of environmental and energy criteria. Metallurgist 54/2011, 600-607.

[12] Toepfer H., Goetze M., Chervakova E., Hutschenreuther T.: On the Use of Wireless Sensors Within a Traffic Monitoring System. Proceedings of the International Academic Forum AMO-SPITSE-NESEFF. Smolensk Publishing "Universum", Moscow-Smolensk 2016.

[13] Torunski E. et al.: A review of smart environments for energy savings. Procedia Computer Science 10/2012, 205-214.

[14] Wang Y., Kuckelkorn J., Liu Y.: State of art review on methodologies for control strategies in low energy buildings in the period from 2006 to 2016. Energy \& Buildings 147/2017, 27-40.

[15] Zhou K. et al.: Big data driven smart energy management: From big data to big insights. Renewable and Sustainable Energy Reviews 56/2016, 215-225.

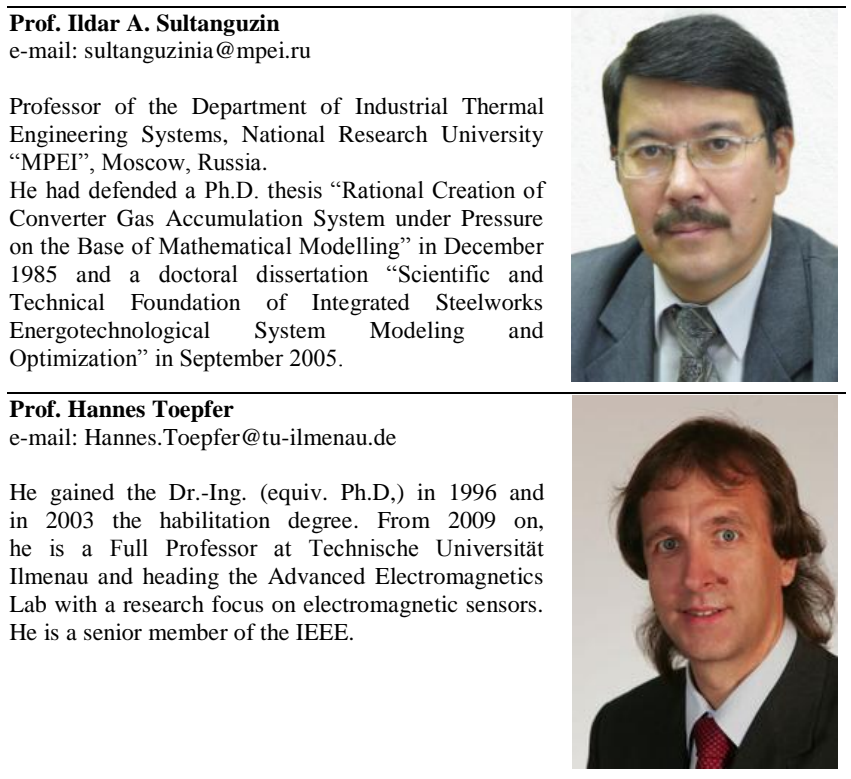

model that were developed via PHPP and the designPH software. First model is needed for optimization of structure and definition of key parameters of energy efficient building. Second model has been used for design of passive house with renewable energy sources in energy supply system. Third model should be used for monitoring and control of energy supply system of nearly zero energy building through year every hour of winter, spring, summer and autumn.

It is necessary to pursue collaborative Russian-German research in decision of optimization task, in modeling of buildings, and in development of monitoring and control of nearly zero energy buildings.

\section{B.Sc. Ivan D. Kalyakin \\ e-mail: albanec1@mail.ru}

I. Kalyakin is a student of Moscow Power Engineering Institute and is getting a Master's Degree course at the department of Industrial Heat-and- power Systems. The theme of the bachelor's work was "The design of energy-supply system of nearly zero energy building". $\mathrm{He}$ is interested in mathematical modeling and have skills of work in such software, as Passive House Planning Package, SketchUp, AutoCad, MathCad, Aspen Hysys.

\section{M.Sc. Alexandr V. Govorin}

e-mail: a.govorin@mail.ru

$\mathrm{He}$ is Ph.D. student at the Department of Industrial Heat Power Engineering Systems, NRU MPEI, Russia

\section{Ph.D. Ekaterina V. Zhigulina}

e-mail: zhigulinayv@mpei.ru

She is associate professor at the Dept. of Industrial Heat Power Engineering Systems, Deputy director of Energy Efficiency Issues Institute, NRU MPEI, Russia.

E. Zhigulina is a co-author of 2 books (in Russian) and around 25 papers in peer-reviewed journals for a total of about 30 papers in journals, book chapters, and conference proceedings.
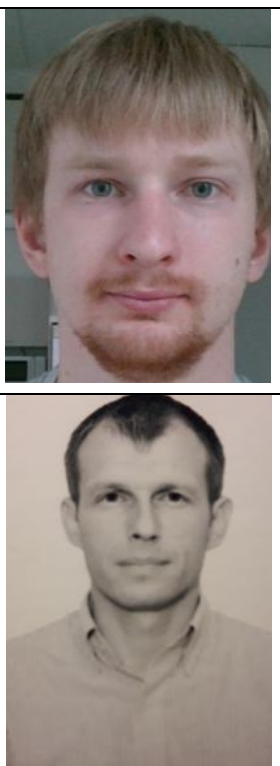

\section{Ph.D. Sergey Yu. Kurzanov}

e-mail: KurzanovSU@mpei.ru

$\mathrm{He}$ is Associate Professor of the Department of Industrial Heat Power Engineering Systems, NRU MPEI, Russia.

$\mathrm{S}$. Kurzanov is a co-author of 2 books (in Russian) and around 15 papers in peer-reviewed journals for a total of about 25 papers in journals, book chapters, and conference proceedings.
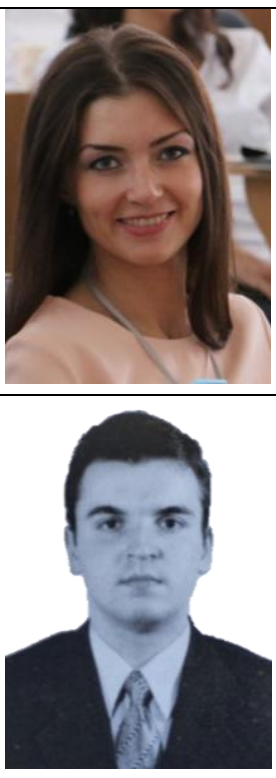

\section{Ph.D. Yury V. Yavorovsky}

e-mail: YavorivskyYV@mpei.ru

$\mathrm{He}$ is Head of the Department of Industrial Heat Power Engineering Systems, NRU MPEI, Russia.

Y. Yavorivsky is a co-author of 4 books (in Russian) and around 32 papers in peer-reviewed journals for a total of about 40 papers in journals, book chapters, and conference proceedings. 